\title{
Object oriented identity construction: A study on subcultures of automobile modification in Turkey
}

Today within consumerism, products become tools of social communication. Symbolic meanings of objects allow individuals to communicate their identities, social status and personal characteristics through products. Moreover, some consumers who are not satisfied by the offerings of the industry, perform some kind of bricolage; not only to create new forms, but also new meanings according to their usage practices. Automobile modification is this kind of form and meaning reproduction. Especially, subcultures of automobile modification perform this activity in order to construct their subcultural identity. In this sense, this paper aims to analyze object oriented identity construction of automobile modification subcultures in Turkey.

keywords consumption, identity, subcultures, automobile modification

\section{Introduction}

Revolutionary developments in information and communication technologies have affected the design activity as they have every aspects of human life. By means of these developments, people become more integrated to everyday practices and strengthen their position at the core of everyday life. Today, both research and practice side of design activity cannot be separated from the user integration. Ken Friedman (2003: 508) recalls Hebert Simon's definition of design, "changing existing situations into preferred ones" and emphasizes the situations, motivations and actions that lead from existing situations to preferred ones should be understood in order to accomplish the goal of design activity. This paper aims to understand the consumption practices consumption practices of subcultures in Turkey performing automobile modification; how they transform their existing automobiles into preferred ones; and by performing automobile modifications, how they give a concrete form to their identity construction.

\section{Consumption and identity construction}

Today, especially in modern societies, individuals are forced to be different and unique (Csikszentmihalyi\&Rochberg-Halton, 1981). Moreover, globalization blurred the boundaries between social differences. Hence, identity has lost its ground from social context and has shifted to a "constructed" and "cultivated" phenomenon (Csikszentmihalyi\&RochbergHalton, 1981: 4; Giddens, 1992: 75). 
In the world that we live in which Baudrillard (1994) calls it hyper-real, as a consequence of modern communication technology, visulality has become more effective than ever. Hereafter, what is consumed is no longer the use value, the real entity of object, but the sign value, the representation of the real. In this environment where consumption has become a symbolic language, one of the most important information that individuals are willing to convey to the others is their identities. Signs embedded to their material entity enable objects to transmit information. Consequently, objects have become an unrepeatable part of identity construction in modern cultures.

\section{Subculture and identity}

Sarah Thornton (1997: 1) defines subculture as "groups of people that have something in common with each other which distinguishes them in a significant way from the members of other social groups". In order to achieve this, members of subcultures use various expression tools which can be both tangible signs; clothing, hair style, vehicles and intangible signs; preferences, behaviors.

According to Stuart Hall and Tony Jefferson (1993) members of subcultures having mostly working-class background, express their rebellion against to the hegemonic structures by these expression tools. Dick Hebdige (2002) does not read these symbolic actions in such a strong behavior like resistance, but still emphasizing the opposing character of subculture which reveals itself as hidden, indirect messages expressed through these symbolic actions. He (2002: 104) discusses the role of commodities in these symbolic actions and the bricolage concept: "placing them (commodities) in a symbolic ensemble which served to erase or subvert their original straight meanings".

\section{The study}

Automobile, as an industrially produced object, is designed for average user with average and standard features. Activity called automobile modification is changing one or more of these features according to the personal demands and desires of users. However, automobile modification is not limited to functional modifications. Enthusiasts perform visual modifications in order to improve the appearance of the automobile and most of the time these modifications have no impact on the performance. Hence, they are based on social and psychological considerations. Especially, subcultures usually perform automobile modification in order to make automobiles represent their identities.

One of the important rituals of automobile modification culture emphasizes this goal: gathering together in the public spaces and showing off automobiles to others. Additionally, virtual communities have also become an important communication medium of these subcultures to show their automobiles and debate on their modifications. Thus, these virtual mediums are rich sources for understanding this activity and paper presented is based on netnographic research of these virtual mediums from which data gathered is analyzed according to the similarity and recurrence.

\section{1 'Façacı Style' automobile modifications}

Façacı and Apaçi terms are used for describing mostly young male members of subcultures in Turkey. Apaçi and Façacı are associated with lowly educated, uncultured, unemployed or working in low paid job young individuals from working-class and immigrant background. They usually live in ghettos and mostly engage in anti-social and sometimes criminal behaviors. 
Façacı subculture can be rooted back to 1980's. However, Apaçi subculture is newly established social group of 2000's, yet they have same social-economic characteristics and they are associated with automobile modification.

Starting from 1950's, the industrialized big cities in the west regions of Turkey have been facing immigration from the rural east regions. Because of the expensive life conditions, migrants have to live in rural-like places in the outskirts of the cities. This geographically isolation has enabled them to preserve their rural lifestyles (Belge, 1990). Overtime, they created their own culture; arabesk-arebesque-or varos-slum-culture; a hybrid culture of city and rural lifestyle. Arabesk culture is based on Arabesk music which merges the rhythms of Arabic music with the use of Western instruments. Likewise, the lifestyle of the new migrant groups in urban spaces also composed of mixture of rural lifestyle and modern urban lifestyle. However, urbanities have never accepted the existence of these groups in cities. They usually look down on to these poor, uneducated, lumpenproletariat habitants of cities which caused alienation between urbanities and migrants and finally these migrants to create enclosed cultural practices in urban spaces. However, migrant culture has gained domination in big cities by the mass immigration in 1980's. Arabesk culture has become unseperatlable part of city life. Modified Faça automobiles and Apaçi automobiles are also part of this slum culture.

Faça is a slang phrase for "scarring on the face or body mostly caused by fight" and façaci means "the person that harms himself with knife or razor". Being façacı is one of the significant rituals among some of the young male fans of Arabesk music; they express their emotional pains through physical pains under the influence of drugs and alcohol, and present their revolt to the otherization and their poor life in cities by listening Arabesk music which expresses same problems.

Façacı have distinctive representation codes: egg-heeled shoes, wearing white socks, listening Arabesk music loudly in public spaces and driving modified TOFAŞ Murat 131 series automobiles, the Turkish versions of the old Fiat 131 series. Façaci style modification also has distinctive characteristics. Although, import trade started by the 1980's, it was still hard to find equipments and products for modification and even it was possible, they still could not be affordable for Façacı. Moreover, there weren't enough skilled workshops performing automobile modifications at that time. Therefore, Façacı style is based on simple, self made and accessory based modifications (Figure 1, 2).

Because of the lack in skilled labor for producing today's heavy body modifications, Façacı style modification is mostly shaped by interior modifications such as using armrests; multiple rearview mirrors; steering wheel covered with imitation leather, wood and cork; dashboard covers; gear shift cases and knobs from several different materials such as knitted beads and billiard ball, and using several interior and exterior accessories such as hanging dice; worry beads; evil eye beads or compact disc to the rearview mirrors; placing plush or knitted cushions over the front and back dashboard; using seat beads; sticking visual and phrase stickers of Arabesk culture and sometimes stickers of religious quotes from Quran.

Using shiny chrome accessories of appealing American automobiles such as door handle, side mirror covers, fuel lid and trunk lid handle, wheel trims and covers, using Hella fog lights cover; wind deflectors; polarized window tinting film; and yellow painted headlight imitating iodine headlights are the characteristic body modifications of Façacı style. 
theme 3

identity

Figure 1

Façacı Style: Interior and body modifications. strand 1

design process and pratice
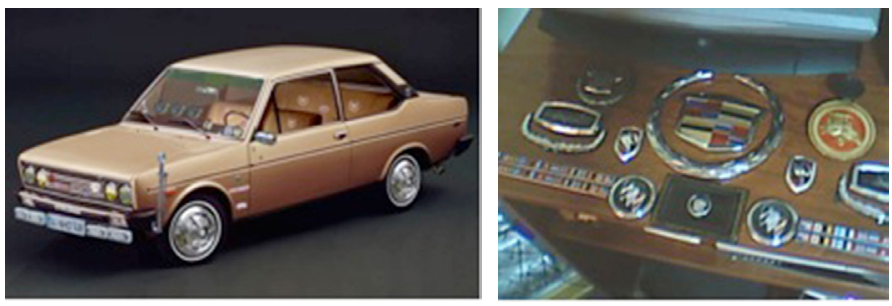

\section{2 'Apaçi Style' automobile modifications}

Perestroikaic neo-liberal politics starting from the late 1980's enabled the import trade and it became easier to find diverse automobile brands, components and accessories. The variety of those components and accessories resulted diversity in automobile modification styles. Moreover, the developments in communication technology has resulted the domination of globalism and global mass culture on daily life by 2000 's. Common global styles such as German Style, JDM Style became also available in Turkish automobile modification culture. Automobile modification has spread out from decorative context into more improved context including complex body, performance and in-car entertainment modifications.

As the progress in communication has enabled visuality more effective in daily life and with theprominence of consumption, identity has affected by this situation. Façacı identity has transformed into more Western and consumption oriented identity called Apaçi and Façacı style has turned into more improved form of modification style called Apaçi Style. Orhan Tekelioğlu (2010) states the term Apaçi can be derived from two different bases; from the resemblance of this subculture's unique dance figures, Apaçi dance, to the ritual dance figures of Native American tribe Apache and from the term "apaș" which means city vagabond.

Although coming from the same background with the older generation Façacı and having similar socio-economic characteristics, Apaçi have different clothing, music and life style. Yet, Apaçi style is also rely on modification of TOFAȘ Murat 131 series, but performing more complex modifications. Apaçi youth are aspired to luxury consumption. However, these low socio-economic status individuals mostly far from being able to afford these products. Hence, they prefer to consume the replicas of them. They perform a bricolage of fake brand commodities.

Apaçi youth are also known by their anti-social, marginal behaviors in the public places such as cursing, smoking, standing and loitering, and dancing their distinctive Apaçi dance accompanied with techno music. Another important feature of Apaçi youth is their tendency on collectivity; wandering, driving, entertaining as packs. All these characteristics make Apaçi youth to be labeled with humiliating phrases by the society: modern hick, lout, and slum parvenu.

Possessing a modified automobile is also another way of expressing the signs of status for them. Apaçi usually prefer cheap but big eye-catching visual modifications which are labeled as tacky, cheap or tasteless by the rest of the society. Common modifications that Apaçi mostly perform are loud sub-woofer sound systems, exaggerated pieces of bodywork and noisy exhaust systems which do not support the performance of the automobile, but pretends to be a high performance automobile. Other minor 
modifications are LED lightning on several surfaces of the car; shinny alloy wheels; fake brand stickers covered on the body and tinted windows.

\section{Conclusion}
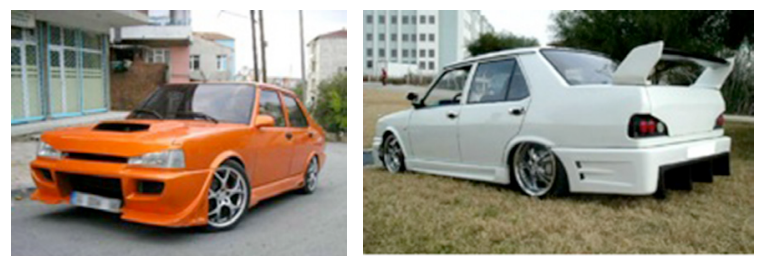

Figure 3.

Apaçi Style: Body modifications.

Although they perform different kind of modification techniques and products, Façacı and Apaçi modification styles both have a show-off character. Façacı Style performs this by using accessory based modifications, Apaçi Style by excessive body modifications and overuse of modification products. We can still state that decoration culture of Façacı Style has maintained by Apaçi Style, yet it has transformed into more global context.

Recalling Thornton's definition of subculture, we can say that these individuals create collective identity that connects them to the members of the subculture and also differentiates them from the others. Coming from working-class background, being lowly educated and living in the outside the center, but still being part of the urban space, Façacı and Apaçi are both urbanities but at the same time outsiders. This hybridity enforces these individuals to express their existence, their identities by differentiating themselves from others through their behaviors, appearances and possessions.

Their desire to be noticed by the others, namely by the center, is realized by their anti-social behaviors, using fake luxury products and performing big noisy eye catching modifications. Their possessions are the representations of social and economic wealthiness which these young working-class individuals emulate. Paradoxically these attempts cause them to be perceived as a ridiculized and humiliated image by the center.

The core characteristic of Façacı and Apaçi modification style is making things "looks like". Like wearing fake luxury products they also modify their automobiles with technically useless yet visual modifications; mostly in order to emulate luxury segment sport automobiles.

One of the significant features of Façacı and Apaçi modification styles is the usage of TOFAS automobiles, because these automobiles, their spare parts and accessories are significantly cheap and easy to repair. Moreover, their body designs are so basic that can be easily modified according to the owners' preferences. In that sense, these automobiles are suitable blank canvases that enable their owners to perform a bricolage: turning an industrial object into a representation of their individualistic expressions through modifications.

These modified automobiles are built for the purpose of "looks like", the representation of the real. Through automobile modification, the members of these subcultures try to give a concrete form to their desire of attracting attention. Belk (1988: 151) states that symbolically automobile has become an extension of the self, a "second skin" which the others see us through it and which we perceive and experience our surrounding through it. By modifying their automobiles, they identify their automobiles with different appearance and themselves with different identities. 
Today, people are living in a society where visuality is intense and communication is a decisive factor is a decisive factor. Especially in modern societies, where modern societies, where objects are used transcending their use value for the favor of sign value, identity and social relations are constructed through consumption. Thus, modified automobiles have become vehicles that serve their owners' social and psychological needs more than their transportation usage.

\section{References}

Baudrillard, J. (1994[1981]). Simulacra and Simulation Glaser, S.F. (trans.), Ann Harbor: The University of Michigan Press.

Belge, M. (1990) 'Toplumsal Değișme ve Arabesk', Birikim, no. 17, pp.16-23.

Belk, R. W. (1988) 'Possessions and the Extended Self', Journal of Consumer Research, vol.15, no. 2, September, pp. 139-168

Csikszentmihalyi, M. and Rochberg-Halton, E. (1981) The meaning of things: domestic symbols and the self, Cambridge: Cambridge University Press.

Giddens, A. (1992) Modernity and Self-identity: Self and Society in the Late Modern Age, Cambridge: Polity Press.

Hall, S. and Jefferson, T. (1993) Resistance Through Rituals: Youth Subcultures in Post-war Britain, London: Routledge.

Hebdige, D. (2002) Subculture: The Meaning of Style, London: Routledge.

Tekelioğlu, O. (2010) 'Apașlardan Apaçilere', Radikal Newspaper. 14th November. Thornton, S. (1997) General Introduction, in Gelder, K. and Thornton, S. (ed.), The subcultures reader, London: Routledge. 
